Research Article

\title{
Research on the Evolution Characteristics of Rock Mass Response from Open-Pit to Underground Mining
}

\author{
Jiabo Geng, ${ }^{1}$ Qihang Li $\left(D,{ }^{1}\right.$ Xiaoshuang Li $\mathbb{D}^{2,3,4,5}$ Tao Zhou, ${ }^{1}$ Zhifang Liu, ${ }^{1}$ and Yulin Xie ${ }^{1}$ \\ ${ }^{1}$ School of Resources and Environmental Engineering, Jiangxi University of Science and Technology, Ganzhou 341000, China \\ ${ }^{2}$ School of Civil Engineering, Shaoxing University, Shaoxing 312000, China \\ ${ }^{3}$ College of Civil Engineering, Qilu Institute of Technology, Jinan 250200, China \\ ${ }^{4}$ Sinosteel Maanshan General Institute of Mining Research Co. LTD., Maanshan 243000, China \\ ${ }^{5}$ State Key Laboratory of Safety and Health for Metal Mines, Maanshan 243000, China \\ Correspondence should be addressed to Xiaoshuang Li; xsli2011@126.com
}

Received 24 June 2021; Accepted 31 July 2021; Published 9 August 2021

Academic Editor: Song Jiang

Copyright (c) 2021 Jiabo Geng et al. This is an open access article distributed under the Creative Commons Attribution License, which permits unrestricted use, distribution, and reproduction in any medium, provided the original work is properly cited.

\begin{abstract}
This study is based on the engineering background of pit no. 2 in Jinning Phosphate Mine, China. In order to systematically analyze the movement, deformation, and failure laws of surrounding rocks in underground stopes. The room and pillar method is used to excavate and stop the ore bodies in the mining area. Combined with the similar physical model experiments and discrete element MatDEM numerical simulations, it reveals the deformation and failure laws and evolution characteristics of the surrounding rock of the stope in the process of converting from open-pit to underground mining. The results show the following: (1) Along the inclination of the ore body, the farther the horizontal and vertical displacements are from the underground stope, the less the impact of mining stress. On the other hand, along the inclined vertical direction of the ore body, the farther the measuring point is from the stope, the smaller the range of mining influence will be. (2) In the process of ore body recovery, the rupture of the overlying strata of the stope has an obvious layered structure, with collapse zones, fissure penetrating zones, and microfracture loosen zones appearing from the bottom to top. In addition, the movement and destruction of the overlying strata of the entire stope is an "elliptical arch." Therefore, the results of similar simulation experiments and numerical simulation are basically consistent.
\end{abstract}

\section{Introduction}

China is one of the largest phosphate mining countries, and its total resources rank second in the world, but the burial is deeper, mostly in inclined deposits. Compared with other open-pit mines, it has the characteristics of difficult mining and high cost [1-3]. In addition, as the country pays more and more attention to environmental governance, open-pit mines have gradually lost the advantages of fast production and high safety index $[4,5]$. Because of this, it is urgent to switch to underground mining. Affected by the mining stress and the gravity of the overlying rock, the stability of the open-pit slope of the underground stope is about $20 \%$ lower than that of the single open-pit mining, which seriously endangers the safety of the open-pit and underground stope
[6]. Therefore, the response of slope rock mass coupled with underground mining is the key issue that affects safe production.

Many scholars have conducted a large number of studies on the instability mechanism, deformation and failure characteristics of open-pit slopes, and deformation and failure characteristics of underground surrounding rocks [7-9]. Jakubec et al. discussed the failure structure of the rock mass on the slope of the Ekati Diamond Mine after open-pit mining was converted to underground mining [10]. Bakhtavar and Shahriar used mathematical economic theory models to predict and analyze the stripping rate and optimal mining time period of open-pit and underground combined mining, which greatly improved the mining efficiency [11]. Brummer et al. used 3DEC (3 Dimension Distinct Element 
Code) to simulate the instability and failure of the high and steep slope on the north side of Palabora Mine during the process of converting from open-pit to underground mining [12]. Mass et al. analyzed the mechanism of the upper pit in the goaf after the Plabora Mine was converted to underground mining [13]. With the continuous improvement of rock mass testing methods, coupled with the introduction of various interdisciplinary advanced theories. Some researchers have conducted a more in-depth discussion on the mechanical mechanism and deformation mechanism of open-pit transfer to an underground stope. Li et al. established a rock slope deformation model for the transition from open-pit to underground mining and analyzed the nonlinear relationship between underground mining disturbance and slope deformation in open-pit mining [14]. Based on the combination of theoretical analysis and numerical simulation, Zhang et al. systematically studied the deformation mechanism of the slope rock mass in the Jinchuan Longshou mining area [15]. Song et al. used similar physical model tests and numerical simulation methods to study the degree of rock deformation during the converting of the Panzhihua Jianshan Iron Mine to underground mining [16]. Jia used similar material simulation tests and a noncontact strain analysis system to monitor the displacement of iron ore from open-pit to underground mining and obtained the effect of underground stopes on open-pit slopes [17]. Wang et al. used numerical simulation methods to study the stress and deformation and failure laws of the slope rock mass under the action of underground mining [18].

The above-mentioned methods are mainly used in the mining of open-pit and steeply inclined open-pit to underground ore bodies and rarely involve gently inclined thin to medium-thick layered nonmetallic phosphate ore. On the other hand, they mainly focused on the actual technical issues of the project, and there is little research on the effect of the open-pit slope on the underground stope and the mechanical mechanism. In short, it is a difficult problem to systematically study the mechanic mechanism and mining response characteristics of the slope rock mass coupled with underground mining after the open-pit to underground mining.

To overcome these challenges, we took the deep ore body of no. 2 pit of Jinning Phosphate Mine as the engineering background and conducted in-depth investigations on the geological characteristics of the mines, the occurrence characteristics of the ore bodies, and the current status of mining in the area. On this basis, MatDEM numerical simulation test, similar physical simulation experiment, and theoretical analysis methods were used to study the evolution characteristics of rock mass response in open-pit mining to underground mining. The comparison of a similar simulation experiment and numerical simulation test verified that the direct roof of the underground stope was destroyed in an "elliptical arch" after the phosphate ore body was converted from open-pit to underground mining. When the internal stress value of the pressure arch exceeds the ultimate strength of the rock layer itself, the rock layer will have four failure modes: compression failure, shear failure, tensile failure, or combined failure.

\section{Engineering Background}

2.1. Mine Profile. As shown in Figure 1, the phosphate mining area is located 72 kilometers southwest of Kunming, China, 2 kilometers on both sides of the southern end of Dianchi Lake. The geographical coordinates are $103^{\circ} 22^{\prime} 16^{\prime \prime}-103^{\circ} 34^{\prime} 42^{\prime \prime}$ east longitude and $24^{\circ} 41^{\prime} 40^{\prime \prime}-24^{\circ} 44^{\prime} 07^{\prime \prime}$ north latitude. The mining area is about 9.2 square kilometers, with county-level highways, quasigauge railways, and expressways nearby, and the transportation is very convenient. According to the preliminary design of the Jinning Phosphate Mine Phase I expansion project, the Jinning Phosphate Mine (III and IV mine sections) \#34 \#130 exploration line is divided into ten open-pit mining from north to south. In this study, we choose the no. 2 mining area (between the \#52 \#66 exploration lines) as the study area. This area is located in the hinterland of the Yunnan Plateau, belonging to the Jinsha River system, and adjacent to the Nanpan River watershed in the south. The mine is a midmountain landform, with cold winters, no sweltering summers, foggy all year round, and an average annual rainfall of $925.4 \mathrm{~mm}$. Currently, affected by open-pit mining and natural weathering, the study area has fully developed fissures, and the ore body is relatively loose (Figure 2).

2.2. Mining Area Structure. The no. 2 mining area (between the \#52 \#66 prospecting line) squeezed from east to west in the early stage, forming the F1-1, F1-2, and F10-01 faults with a nearly north-south strike. Later, it was extruded from the NWSSE direction to form the F2-4 fault in the NEE-SW direction. The structure is simple, and no folds are developed. In addition, the stratum and the ore layer slope to the east and produce monoclinic.

\subsubsection{Near North-South Faults}

F1-1 Fault. It is a regional large fault (a reverse fault), which runs through the entire Jinning Phosphate Mine in a nearly north-south direction, distorting the stratum and ore layers and forming two major ore bodies (layers) in the east and west. The fault plane is inclined to the east, with a dip angle of $65^{\circ} \sim 70^{\circ}$, and a length of about $9530 \mathrm{~m}$.

F1-2 Fault. The reverse fault strike is $\mathrm{N} 15^{\circ} \mathrm{W}$, and the total length is about $2588 \mathrm{~m}$. Among them, the extension length in the area is about $584 \mathrm{~m}$, and the curvature is relatively large near the \#57 exploration line. The fault plane is inclined to the east, with a dip angle of $63^{\circ} \sim 70^{\circ}$. The fault has no effect on the continuity of the ore body, which is located on the east side.

F10-01 Fault. The length of the reverse fault is about $107 \mathrm{~m}$, the fault plane is inclined to the east, and the dip angle is about $68^{\circ} \sim 71^{\circ}$. The extension is short and the scale is small, causing failure to the ore bodies in a small area on the north and south sides of ZK54-2.

\subsubsection{Northeast-Southwest Fault}

F2-4. The fault is a flat-reverse fault with a length of about $129 \mathrm{~m}$. After geological investigation, the northwest plate slides in the southwest direction, and the 




Figure 1: Geographical map of no. 2 mining area of Jinning Phosphate Mine.

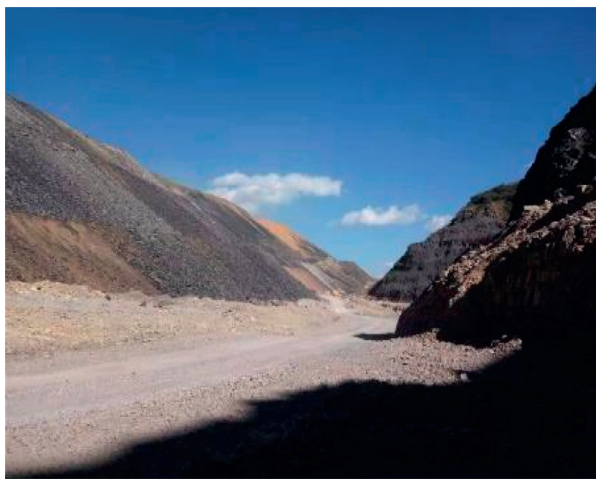

(a)

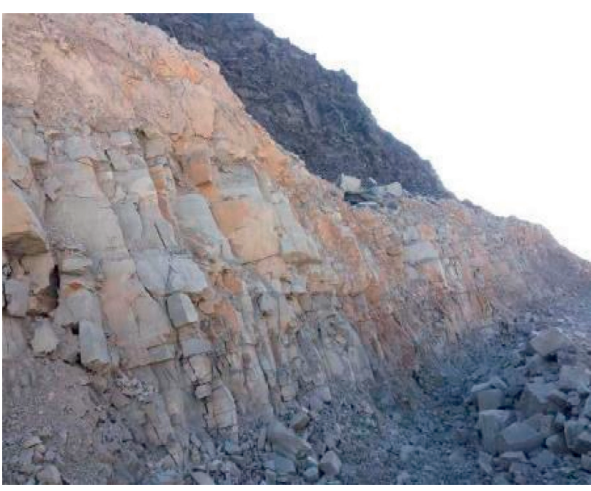

(b)

Figure 2: The mining status of Jinning Phosphate Mine no. 2 pit. (a) Current status of surface mining. (b) Development of fissures in openpit mining at this stage.

southeast plate slides in the northeast direction. The sliding distance is about $29 \mathrm{~m}$. Affected by this, the ore body outcrops between \#62 and \#63 exploration lines formed dislocation.

2.3. Stope Stability Investigation. According to the direction of the investigated dominant structural surface, a stereographic projection map is drawn. As shown in Figure 3(a), the azimuth angle of the strip arrangement can be roughly divided into five regions. Based on the stereographic projection map (Figures $3(\mathrm{~b})-3(\mathrm{f})$ ), the stability of the stope was judged and analyzed in five areas:

(1) As shown in Figure 3(b), the stope axis of Zone 1 is obliquely intersected with the strikes of the two sets of structural planes, and the inclination angle of the structural plane $l_{1}$ is relatively slow. The distribution of structural planes has a greater impact on the stability of the stope. The main deformation forms may be gangsters and roof failures.

(2) As shown in Figure 3(c), the stope axis of Zone 2 is almost orthogonal to $l_{2}$, and the $l_{2}$ structure has little effect on the stability of stope strips. The stope axis in Zone 2 is almost parallel to $l_{1}$, and the inclination of the structural plane of $l_{1}$ is relatively slow. Thus, the distribution of structural planes has a greater impact on the stability of the stope, and roof fall is prone to occur.

(3) In Figures 3(d)-3(f), the stope axis of Zone 3, Zone 4, and Zone 5 obliquely intersect with the direction of the two sets of structural planes, which is easy to 


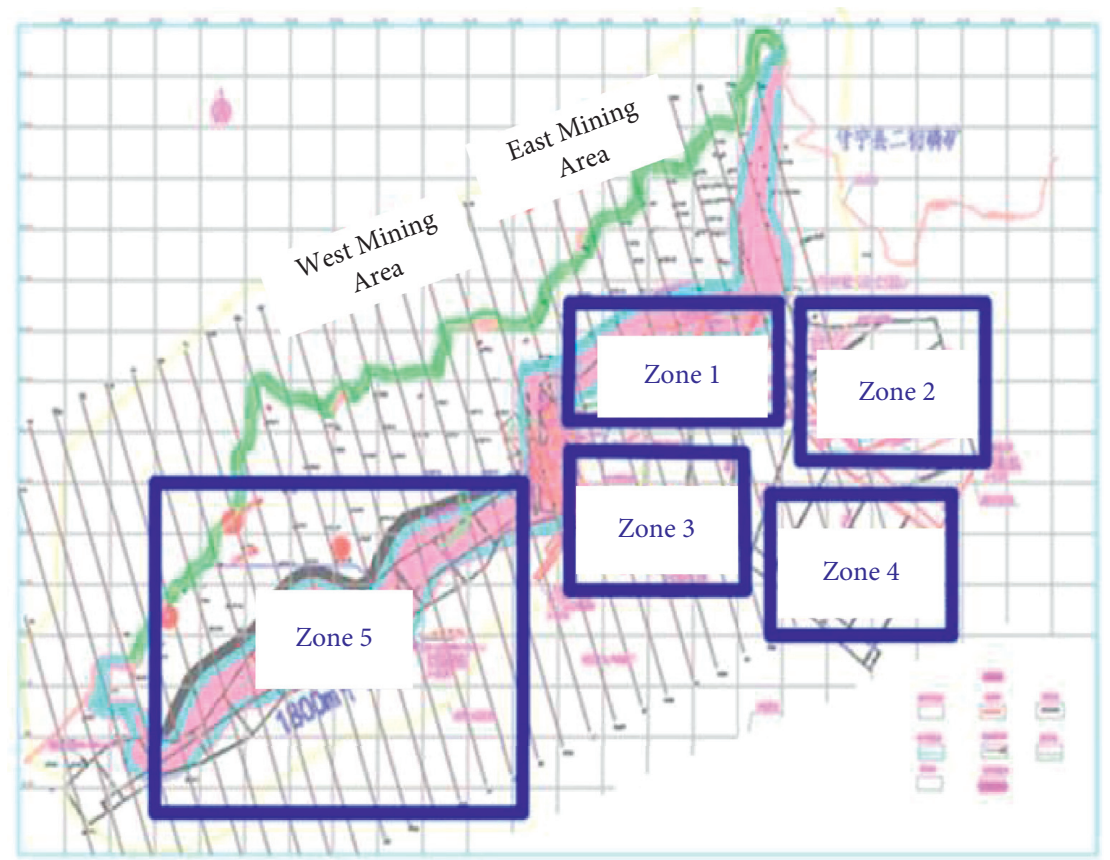

(a)

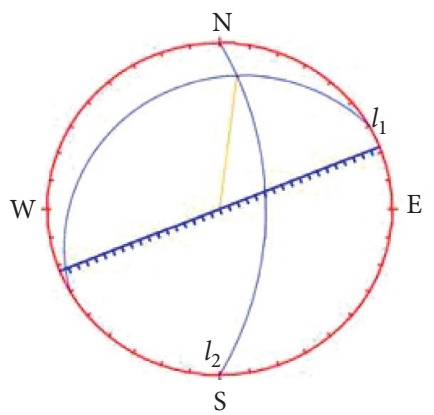

(c)



(e)

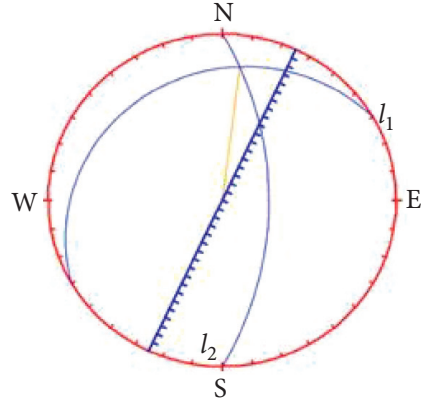

(b)

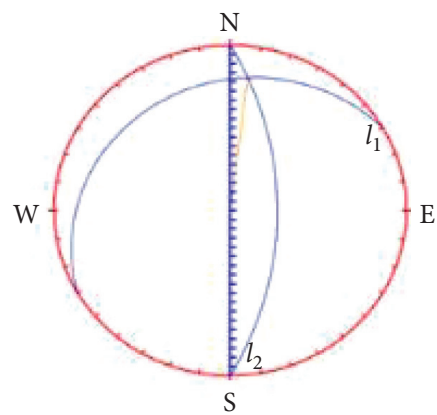

(d)

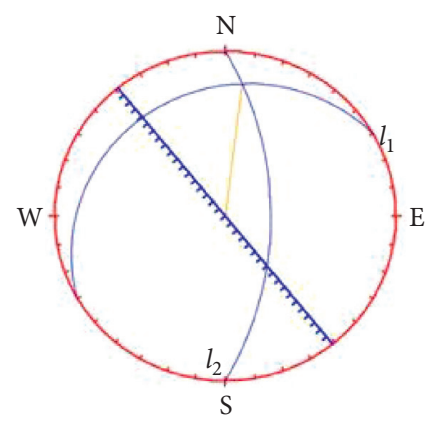

(f)

Figure 3: Stereographic projection of different regions. (a) Area division map; (b) stereographic projection in zone 1; (c) stereographic projection in zone 2; (d) stereographic projection in zone 3; (e) stereographic projection in zone 4; (f) stereographic projection in zone 5.

form unstable bodies and cause the occurrence of roof fall and film gang.

\section{Similar Material Experiments}

3.1. Model Design. As shown in Figure 4(a), the similar physical experiment model frame is composed of a pressurized lever, pressurized panel, top beam, side beam, bottom beam, and model surface steel plate. The model size is $2.00 \mathrm{~m} \times 0.3 \mathrm{~m} \times 1.5 \mathrm{~m}$ (length $\times$ width $\times$ height), the lever loading range is $0.1 \sim 200 \mathrm{MPa}$. In this test, the ground stress was simulated by self-weight loading. To better simulate actual mining, this test finally selected the hanging wall section of the \#59 exploration line as the study area, with a dip angle of $14^{\circ}$ and a layer thickness of $3.4 \mathrm{~m}$ (Figure 4(b)). Table 1 shows the rock mechanical parameters measured by 


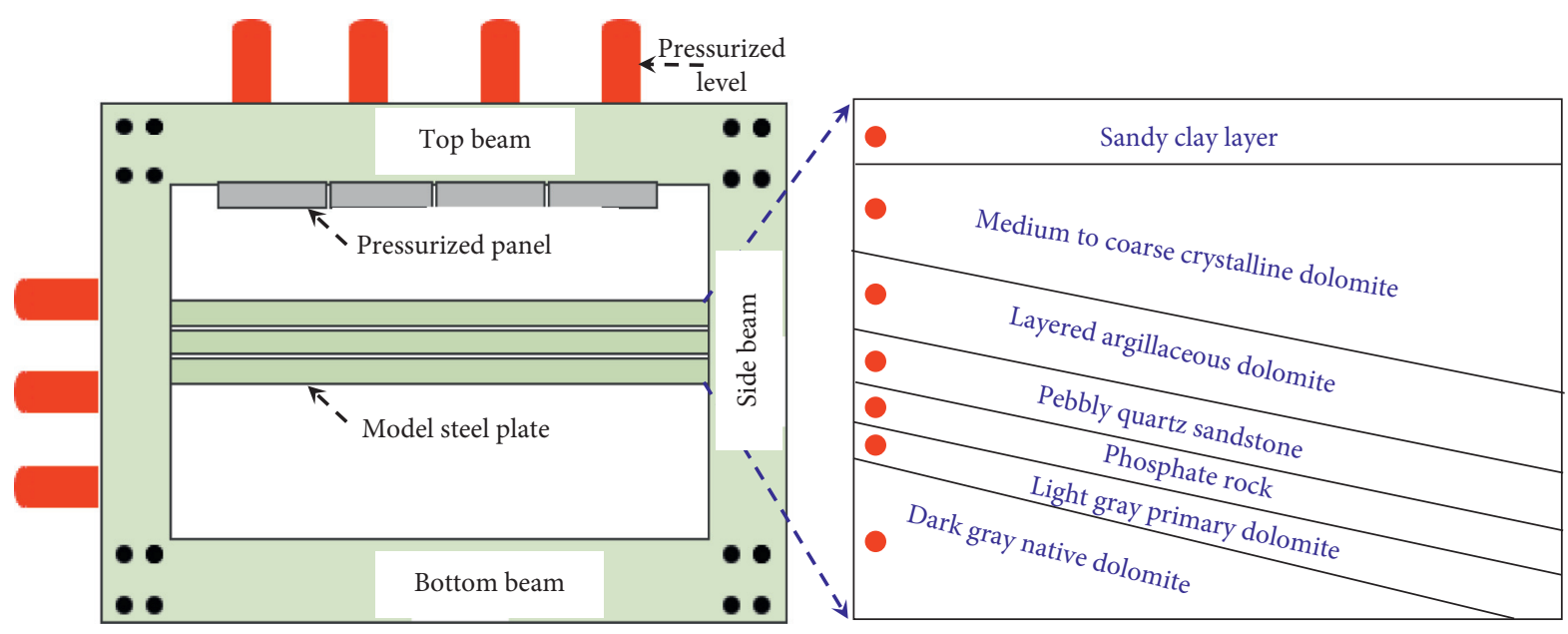

(a)

(b)

Figure 4: (a) Similar model; (b) similarity simulation experiment profile.

TABLE 1: Rock mechanics parameters table.

\begin{tabular}{|c|c|c|c|c|c|c|}
\hline Rock name & $\begin{array}{c}\text { Uniaxial } \\
\text { compressive strength } \\
(\mathrm{MPa})\end{array}$ & $\begin{array}{l}\text { Elastic modulus } \\
\qquad(\mathrm{GPa})\end{array}$ & $\begin{array}{l}\text { Tensile strength } \\
(\mathrm{MPa})\end{array}$ & Poisson's ratio & Cohesion (MPa) & $\begin{array}{c}\text { Internal friction } \\
\text { angle }\left({ }^{\circ}\right)\end{array}$ \\
\hline Sandy clay layer & 45.68 & 24.32 & 4.65 & 0.26 & 18.63 & 32.12 \\
\hline $\begin{array}{l}\text { Medium to coarse } \\
\text { crystalline dolomite }\end{array}$ & 48.25 & 35.43 & 6.38 & 0.15 & 14.69 & 34.22 \\
\hline $\begin{array}{l}\text { Layered argillaceous } \\
\text { dolomite }\end{array}$ & 74.12 & 32.54 & 7.87 & 0.17 & 18.60 & 44.36 \\
\hline $\begin{array}{l}\text { Pebbly quartz } \\
\text { sandstone }\end{array}$ & 78.41 & 49.12 & 6.61 & 0.25 & 22.53 & 49.75 \\
\hline Phosphate rock & 87.49 & 45.36 & 12.73 & 0.32 & 28.70 & 54.78 \\
\hline $\begin{array}{l}\text { Light gray primary } \\
\text { dolomite }\end{array}$ & 63.71 & 46.72 & 11.59 & 0.19 & 18.42 & 53.17 \\
\hline $\begin{array}{l}\text { Dark gray native } \\
\text { dolomite }\end{array}$ & 88.62 & 52.49 & 14.37 & 0.10 & 25.94 & 44.25 \\
\hline
\end{tabular}

laboratory physical tests after field sampling, which reflects the mechanical properties of rock, and the similar physical model experiment material ratio is also based on the mechanical parameters [19].

Based on the principle of similar material simulation, the similarity parameters for each simulation test are as follows: intensity similarity ratio $=1: 500$, Poisson's ratio, strain, internal friction angle $=1: 1$, time similarity ratio $=1: 17$, and bulk density similarity ratio $=5: 8$. A plane stress model was used in the present work to simulate similar materials along the dip materials, sand, gypsum, calcium carbonate, mica powder, soft glue, engine oil, fine wood chips, and water [20-22]. The final selection of the ratio of the measured value of the material parameters and the theoretical value of the least error are combined with the measured actual rock mechanics parameters (Table 2).

3.2. Measuring Point Layout. In this experiment, the design slope height of the final slope after open-pit excavation is $200 \mathrm{~m}$, and the slope angles is $65^{\circ}$. The purpose is to systematically analyze the law of rock mass movement and deformation. As shown in Figure 5, the similar model is along the direction of the ore body, dividing the $24 \mathrm{~m}$ boundary pillar and the three-stage mine rooms and pillars (the size of the mine room is $10 \mathrm{~m}$, the pillar size is $6 \mathrm{~m}$, and the continuous pillar is $15 \mathrm{~m}$ ). In detail, each stage of the excavation is divided into two steps, and the excavation time interval of each mining room is $2.5 \mathrm{~h}$. The mining sequence of the pillars is as follows: the three-stage excavation is completed, and the pillars shall be recovered in sequence (the interval of mining is $2 \mathrm{~h}$ ). In addition, a total of 5 displacement measuring lines are arranged along the normal direction of the ore body at the displacement measuring points, which are, respectively, arranged above each stope and above the pillars.

3.3. Experimental Phenomena. After the first-stage excavation of the model with a slope height of $200 \mathrm{~m}$ and a slope angle of $65^{\circ}$, affected by the mining stress of the underground stope, arc-shaped separation fissures of varying degrees appeared above the roof. The roof collapsed in the upper left corner of mine room \#1 (Figure 6(a)). After the second stage of excavation, pillar \#1 has a shear fracture fissure. In addition, the pillars tended to fall, and 
TABLE 2: Similar material ratio scheme.

\begin{tabular}{lcccc}
\hline Lithology & $\begin{array}{c}\text { Simulated } \\
\text { thickness }(\mathrm{cm})\end{array}$ & Actual strength $(\mathrm{kPa})$ & Simulation strength $(\mathrm{kPa})$ & $\begin{array}{c}\text { Material ratio } \\
(\text { sand : lime: gypsum) }\end{array}$ \\
\hline Sandy clay layer & 10 & 2.19 & 4.38 & $6: 7: 3$ \\
Medium to coarse crystalline dolomite & 69.7 & 35.16 & 70.32 & $2.5: 1.4: 8.8$ \\
Layered argillaceous dolomite & 23.5 & 24.78 & 49.56 & $2.8: 3.5: 6.5$ \\
Pebbly quartz sandstone & 8 & 22.87 & 45.74 & $3: 1: 9$ \\
Phosphate rock & 4.3 & 38.54 & 71.68 & $2.4: 1.2: 9$ \\
Light gray primary dolomite & 2.3 & 39.35 & 78.7 & $2.4: 1: 9$ \\
Dark gray native dolomite & 50.0 & 34.17 & 68.34 & $2.45: 1.5: 8.5$ \\
\hline
\end{tabular}

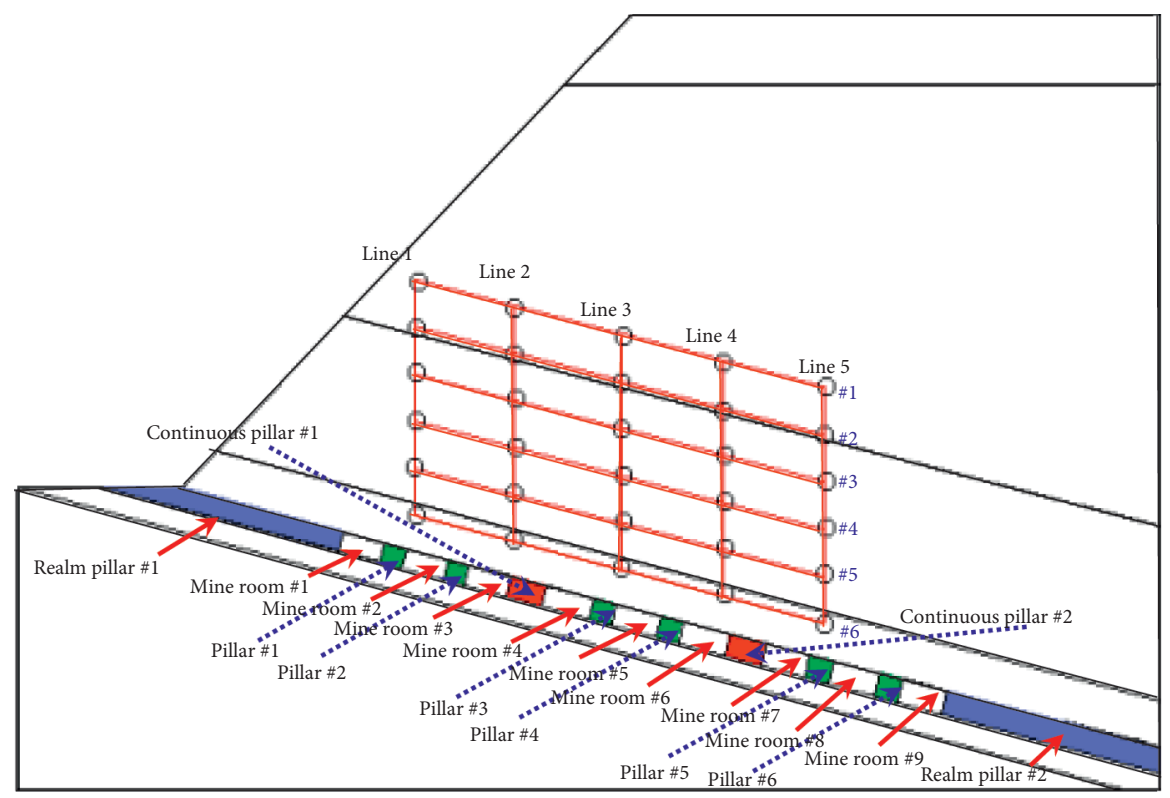

FIGURE 5: Displacement survey line monitoring diagram of a similar physical model.



(a)

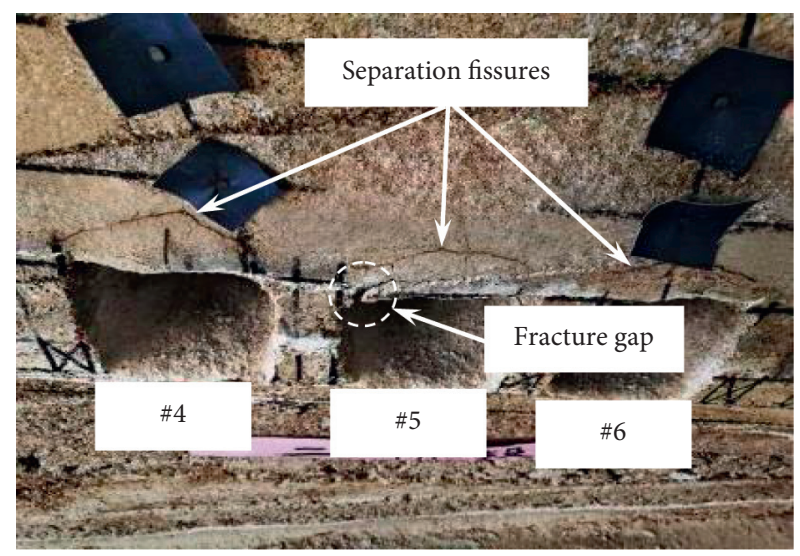

(b)

Figure 6: Continued. 


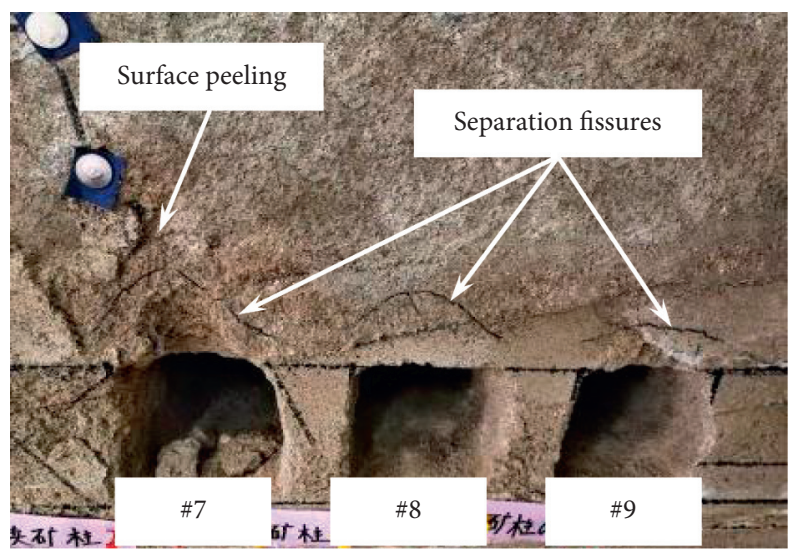

(c)

Figure 6: Failure characteristics of underground stope after (a) first-stage excavation, (b) second-stage excavation, and (c) third-stage excavation under the model of slope height of $200 \mathrm{~m}$ and slope angle of $65^{\circ}$.

microfissures appeared inside the direct roof. With the gradual advancement of the working face, the microfissures developed into arc-shaped through fissures (Figure 6(b)). The reason is that due to the mining stress of the entire stope and the weight of the overlying rock mass, the roof center has been unloaded and collapsed. However, the stress transfers to the surrounding rocks and pillars of the stope, resulting in a phenomenon of pressure arch, which maintains the stability of the stope. During the third-stage excavation, the redistribution of stress will cause the span of the pressure arch to become larger, a large-scale collapse occurs, and a small pressure arch will be formed behind the neighboring stope. Among them, the surface layer of the overlying rock began to fall off, and the collapse was the most obvious (Figure 6(c)).

To better clearly understand the deformation and failure characteristics of the surrounding rock in the underground stope of room and pillar mining, we recovered the isolated pillars in the stope in turn (Figure 7). As shown in Figure 7, after the recovery of the pillars was completed, the overburden failure of the stope caused a large-scale sliding failure trend, with a typical "domino effect." According to the degree of deformation and failure, it can be divided into roof collapse zone, fissure penetration zone, and microfracture loose zone. In other words, under the influence of the superimposed force of mining, the pillars of the stope are in a critical failure state. When any pillar is mined, it will cause plastic failure to its surroundings, thereby threatening the stability of the stope.

3.4. Physical Modeling Result Analysis. As shown in Figure 8, the vertical displacement of the surrounding rock and overlying strata at various stages of the model excavation was measured using a digital camera system. Figures $8(a)-8(c)$ are the subsidence displacements after the first, second, and third excavation stages of the similar material model, respectively. Here, the distance from the beginning of the ore body and the extent of subsidence are plotted as negative values [23].
These experimental results indicate that the deformation of the surrounding rock underground and the overlying strata during mining occurs in the following stages: (1) A small area of the roof fell off during the first excavation stage (Figure 8(a)). (2) In the second excavation stage, the microfissures developed into perforated fissures and collapsed (Figure 8(b)). (3) Large-scale collapse occurred during the third excavation stage (Figure 8(c)).

In detail, after the completion of the first stage of excavation, it advanced $27 \mathrm{~cm}$ in the inclined direction of the ore body (actual engineering $81 \mathrm{~m}$ ). The roof above mine room \# 1 began to show fissures caused by the bending and sinking of the separation layer, and the direct roof on the upper left side collapsed, forming an arched structure. Among them, the maximum horizontal displacement was $-0.164 \mathrm{~mm}(-4.92 \mathrm{~cm})$, and the maximum vertical displacement was $-0.283 \mathrm{~mm}(-8.50 \mathrm{~cm}$ ) (Figure $8(\mathrm{a})$ ). It continued to advance $73 \mathrm{~cm}$ (actual engineering $219 \mathrm{~m}$ ) along the inclined direction of the ore body (the second excavation stage). At this time, the separation fissures extended from the top of the stope from bottom to top, and the upper left corner of mine room \#5 had a fall, and pillar \#5 had broken microfractures. The maximum horizontal displacement and the maximum vertical displacement were increased to $-0.376 \mathrm{~mm}(-11.29 \mathrm{~m})$ and $-0.775 \mathrm{~mm}(-23.27 \mathrm{~cm})$, respectively (Figure $8(\mathrm{~b})$ ). When the third excavation stage advanced to $119 \mathrm{~cm}$ (actual engineering $357 \mathrm{~m}$ ), the space of the stope was further enlarged, causing a large-scale collapse of the overlying rock of the stope. Meanwhile, the maximum horizontal displacement and the maximum vertical displacement reached $-0.423 \mathrm{~mm}(-12.68 \mathrm{~cm})$ and $-0.999 \mathrm{~mm}$ $(-29.97 \mathrm{~cm})$, respectively (Figure $8(\mathrm{c})$ ).

In a word, due to the influence of the mining stress in the underground stope, different degrees of separation fissures appeared on the roof at different stages. After the initial stage of excavation, the overall model was in a stable state, but the roof collapsed in the upper left corner of mine room \#1. After the second stage of excavation, a shear fracture fissure appeared in pillar \#1, and a microfracture 


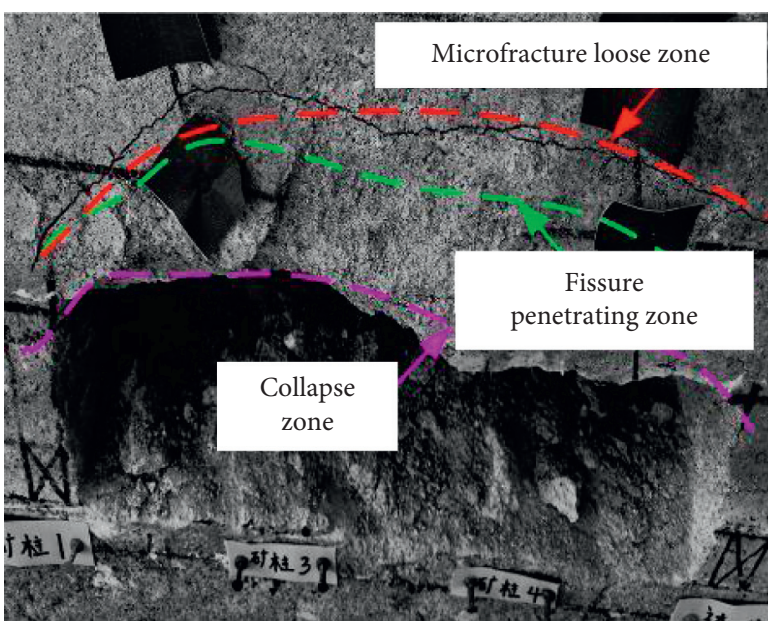

(a)

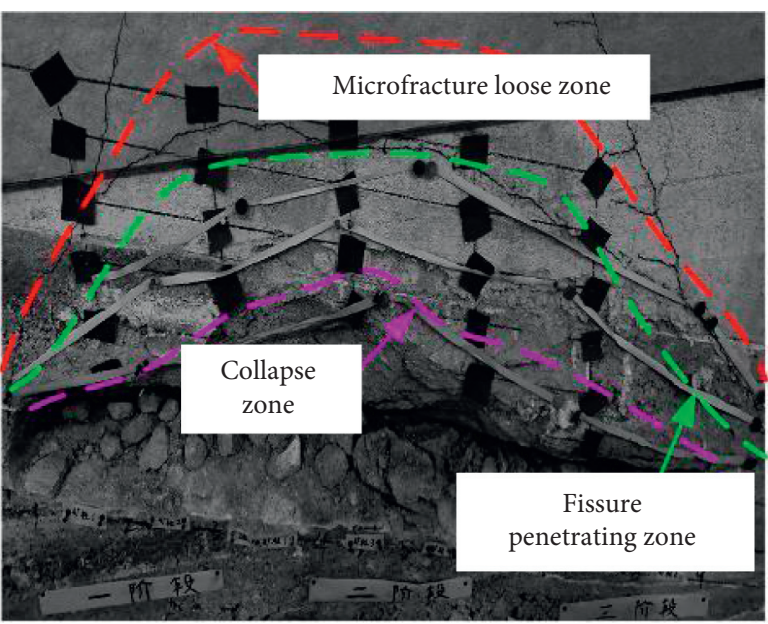

(b)

FIGURE 7: The failure characteristics of the overlying rock mass at the stage of recovering the pillars. (a) Recover pillar \#3 and pillar \#4; (b) recover the continuous pillar \#2.

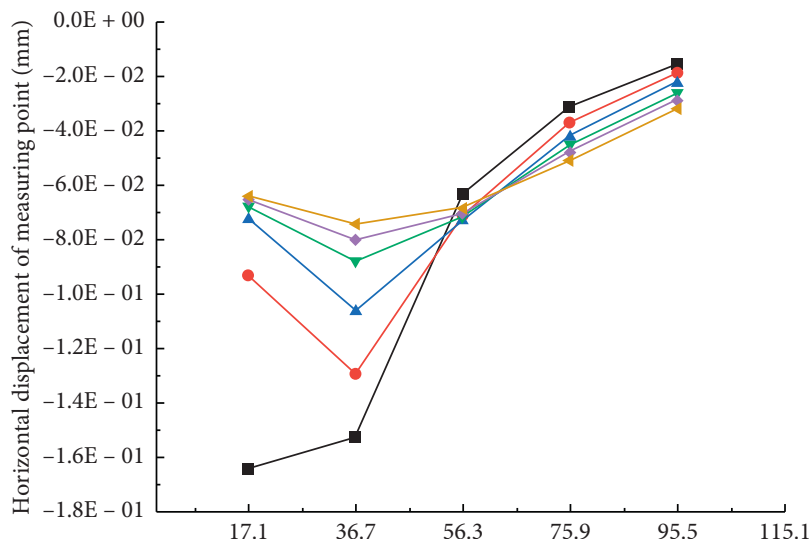

Distance from the initial excavation of the underground stope $(\mathrm{cm})$

$\begin{array}{ll}\rightarrow-\text { Distance } 20.1 \mathrm{~m} & \longrightarrow \text { Distance } 80.4 \mathrm{~m} \\ \longrightarrow \text { Distance } 40.2 \mathrm{~m} & \longrightarrow \text { Distance } 100.5 \mathrm{~m} \\ \rightarrow \text { Distance } 60.3 \mathrm{~m} & \longrightarrow \text { Distance } 120.6 \mathrm{~m}\end{array}$

(a)

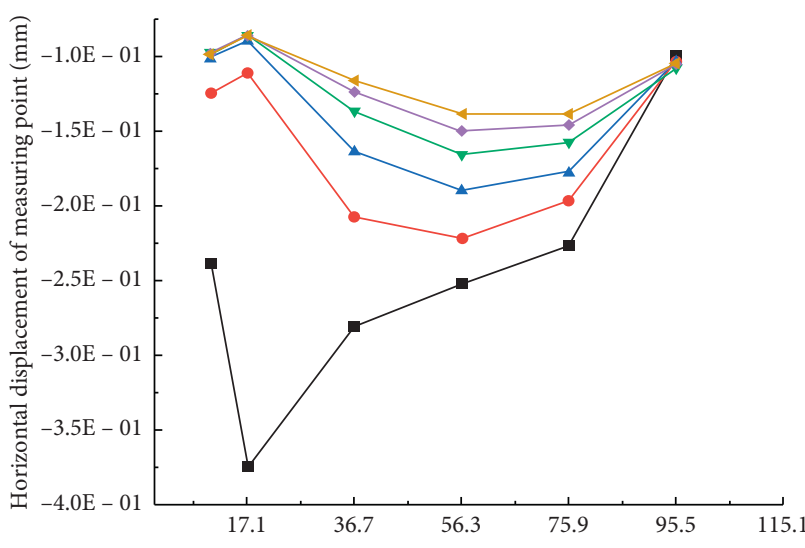

Distance from the initial excavation of the underground stope $(\mathrm{cm})$





Distance from the initial excavation of the underground stope $(\mathrm{cm})$



(b)

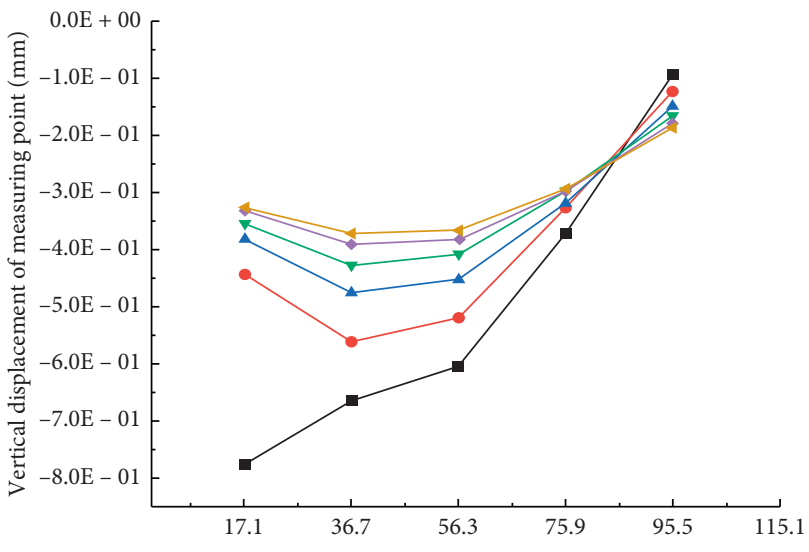

Distance from the initial excavation of the underground stope $(\mathrm{cm})$



(d)

FIgURE 8: Continued. 


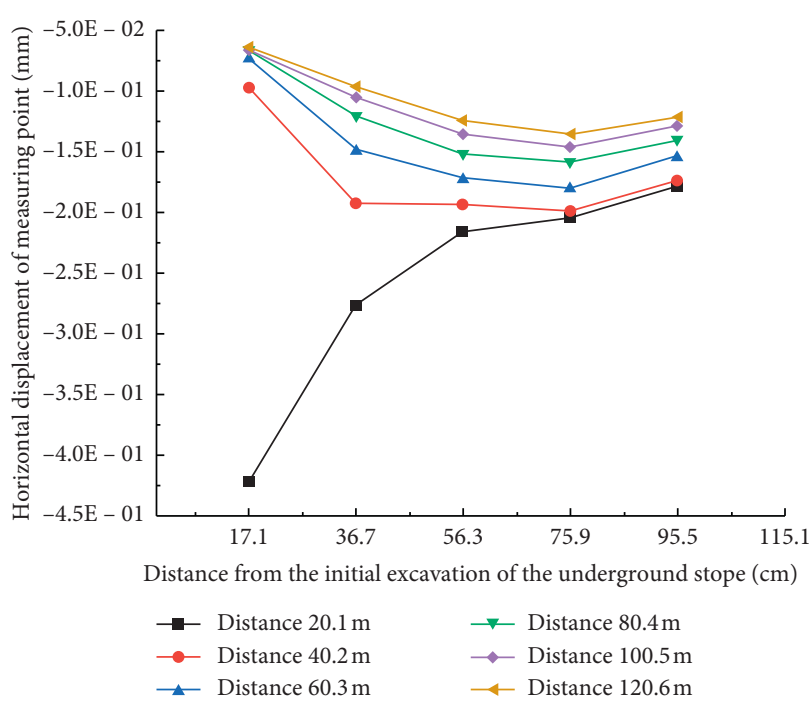

(e)

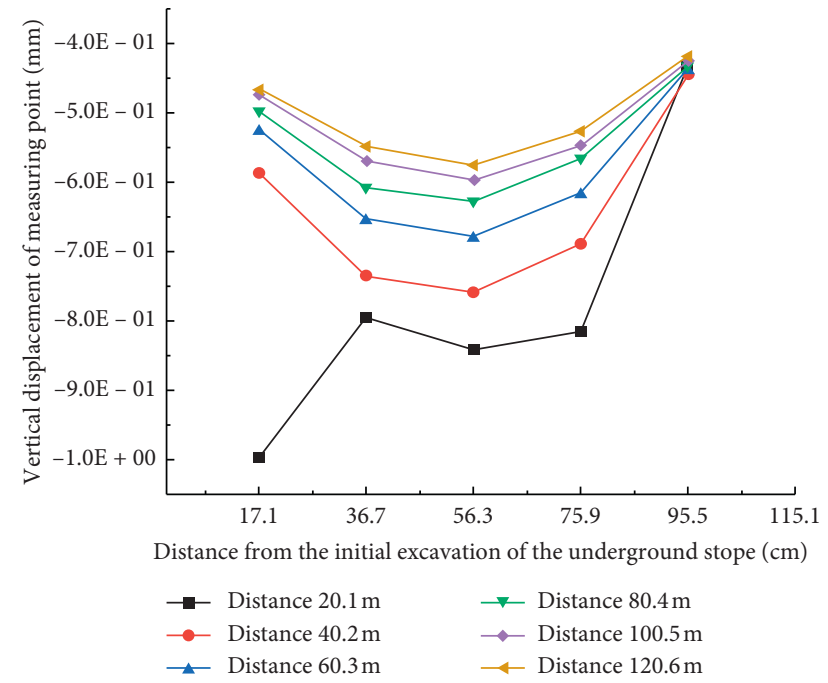

(f)

Figure 8: The model with a slope height of $200 \mathrm{~m}$ and a slope angle of $65^{\circ}$; the three-stage mining displacement curve of the underground stope. Mining displacement curve in (a) the first stage, (b) the second stage, and (c) the third stage.

appeared in the direct roof. With the continuous advancement of the working face, the microfractures developed into arc-shaped through fissures. The reason was that due to the mining stress of the entire stope and the selfweight of the overlying rock mass, there was unloading in the center of the roof, causing caving [24, 25]. When the last stage of excavation is carried out, the redistribution of stress will cause the span of the pressure arch to become larger, until the mining reaches a certain span, and a large-scale collapse occurs.

\section{Numerical Simulation of Rock Mass Movement Characteristics}

4.1. Model Establishment and Assumptions. In recent 20 years, computer technology has developed rapidly, and numerical simulation has become an important research method [26-28]. Based on the measurement results of rock mechanics parameters (Table 1), the following assumptions are made for the numerical model: (1) The ore body model is an ideal elastoplastic body under the ideal Mohr-Coulomb criterion. (2) Each layer of rock is made of homogeneous and homogeneous materials. (3) Ignore the influence of ore body groundwater and other geological structures. Figure 9(a) shows the MatDEM model diagram, and Figure 9(b) shows the initial state of the model.

4.2. Physical and Mechanical Parameters of the Rock. The mesomechanical parameters of the MatDEM model were based on the measured mechanical properties of rock samples obtained on-site. Whether the numerical simulation results are reliable or not mainly depends on the determination of rock mass mechanical parameters. In order to solve this problem, this paper introduced the Hoek-Brown empirical formula to weaken the upper and lower rock layers of the ore layer. The mechanical parameters of the weakened rock mass after numerical simulation are as shown in Table 3.

4.3. Numerical Simulation Model Excavation Scheme. As shown in Figure 9(a), the boundary pillar, the main mine room, and the continuous pillar were divided along the direction of the ore body. Open the mining rooms in order from left to right. Among them, the width of each mine room was $10 \mathrm{~m}$, and the thickness of the boundary pillar was $24 \mathrm{~m}$. To meet the safety requirements of underground mining, each of the three mine rooms was regarded as a mining stage (a total of three stages), and a 6-meter-wide interval pillar (a total of 6) was set between each mine. In addition, two continuous pillars ( $15 \mathrm{~m}$ wide) were reserved after each stage of mining is completed. On the other hand, in order to further study the change law of the overlying rock stress field and displacement field of the stope, we arranged a monitoring line composed of 25 monitoring points $20 \mathrm{~m}$ above the stope (the area circled in black).

\subsection{MatDEM Simulation Results and Analysis}

4.4.1. Rock Mass Stress Distribution Law. In the physical model with a slope height of $200 \mathrm{~m}$ and slope angle of $65^{\circ}$, under the influence of mining stress, some small archshaped microfissures appeared on the top of the stope at the first stage, and the rock mass was in a stable state (Figure 10(a)). With the unfolding of the second stage of excavation, the overhang area of the roof gradually increased, and the unloading range of the stope roof is further expanded. Later, the microfissures in the roofs of various mine rooms gradually penetrated to form multiple macrofissures, and these macrofissures gradually extended to the 


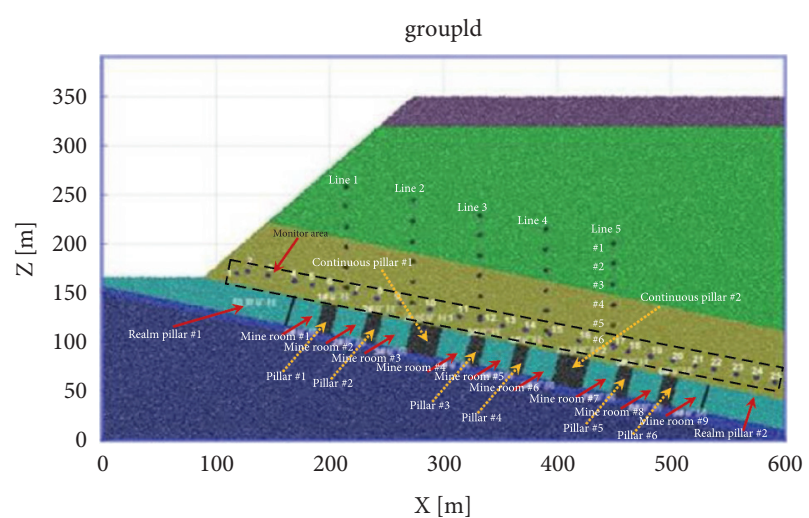

(a)



(b)

FIGURE 9: Numerical simulation physical model. (a) Schematic diagram of the layout of monitoring points for mine rooms and pillars. (b) Stress distribution in the initial state of rock mass.

TABLE 3: Rock mechanics parameters.

\begin{tabular}{|c|c|c|c|c|c|c|}
\hline Rock name & $\begin{array}{c}\text { Compressive strength } \\
(\mathrm{MPa})\end{array}$ & $\begin{array}{c}\text { Elastic modulus } \\
(\mathrm{GPa})\end{array}$ & $\begin{array}{c}\text { Tensile strength } \\
(\mathrm{MPa})\end{array}$ & $\begin{array}{l}\text { Poisson's } \\
\text { ratio }\end{array}$ & $\begin{array}{c}\text { Cohesion } \\
(\mathrm{MPa})\end{array}$ & $\begin{array}{c}\text { Internal friction } \\
\text { angle }\left({ }^{\circ}\right) \\
\end{array}$ \\
\hline Sandy clay layer & 2.19 & 9.96 & 1.25 & 0.15 & 1.51 & 19.0 \\
\hline $\begin{array}{l}\text { Medium to coarse } \\
\text { crystalline dolomite }\end{array}$ & 35.16 & 35.43 & 1.25 & 0.28 & 3.86 & 29.85 \\
\hline $\begin{array}{l}\text { Layered argillaceous } \\
\text { dolomite }\end{array}$ & 24.78 & 25.84 & 0.92 & 0.25 & 4.08 & 29.66 \\
\hline Pebbly quartz sandstone & 22.87 & 17.52 & 0.67 & 0.26 & 5.25 & 29.52 \\
\hline Phosphate rock & 37.96 & 28.40 & 0.88 & 0.3 & 5.64 & 30.53 \\
\hline $\begin{array}{l}\text { Light gray primary } \\
\text { dolomite }\end{array}$ & 39.35 & 30.19 & 1.66 & 0.21 & 6.05 & 30.17 \\
\hline Dark gray native dolomite & 34.17 & 26.80 & 0.72 & 0.23 & 5.42 & 30.32 \\
\hline
\end{tabular}

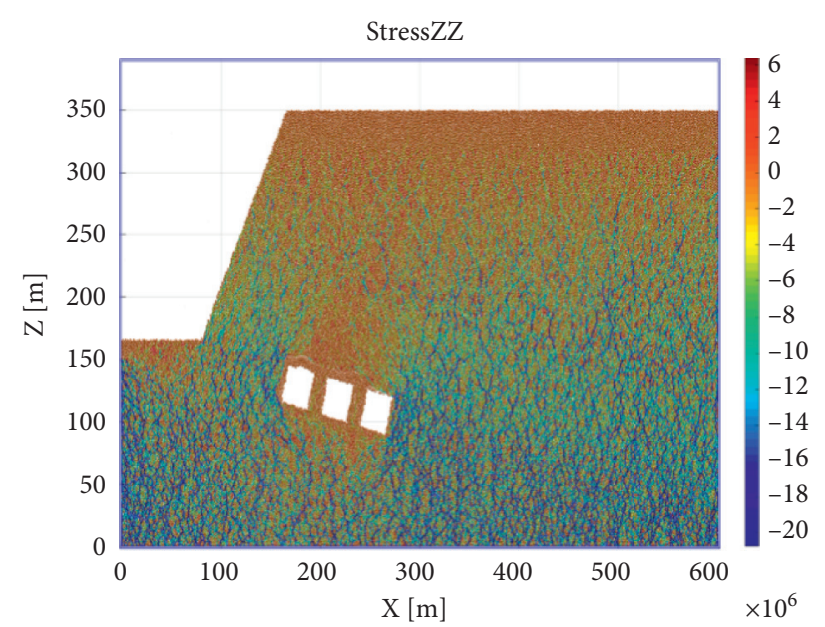

(a)

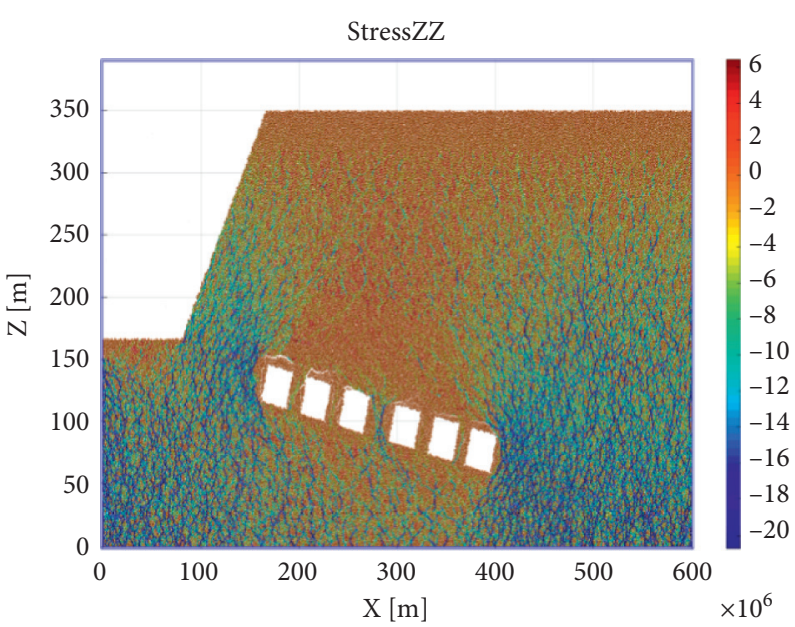

(b)

Figure 10: Continued. 


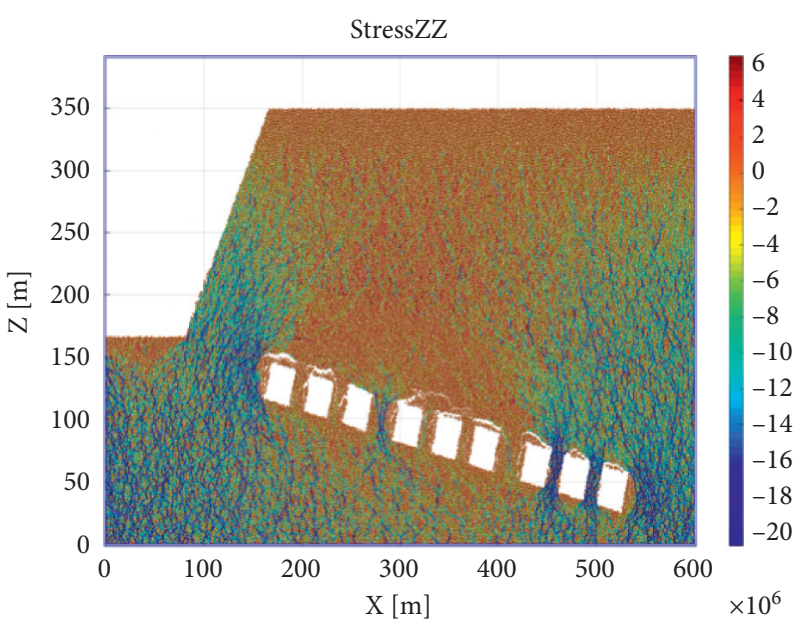

(c)

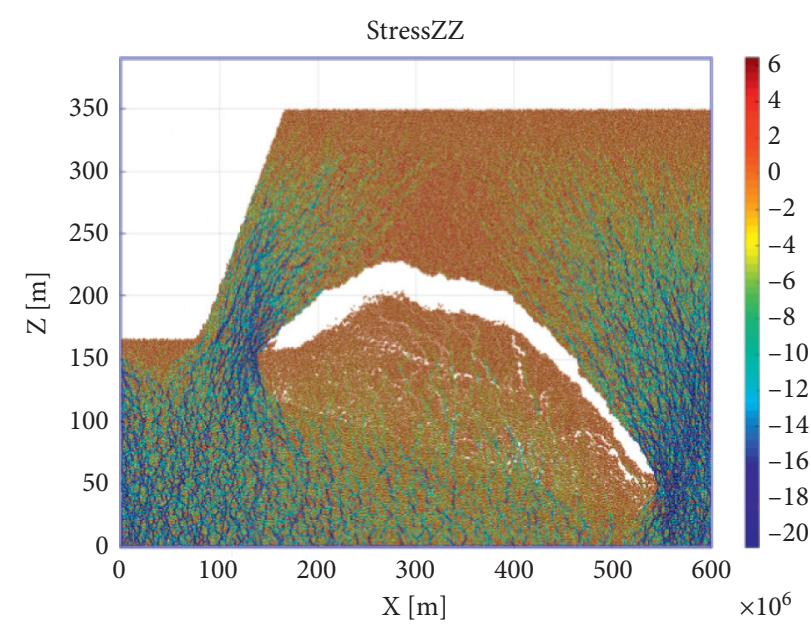

(d)

Figure 10: The stress distribution of the excavated rock mass in (a) the first stage, (b) the second stage, (c) the third stage, and (d) the stoping stage.

old roof and the load layer. After the completion of the second stage of excavation, the exposed area of the stope roof further increased. Affected by the mining stress and the weight of the overlying rock, the ore pillars and their boundary ore pillars bear more and more loads [29]. When the ultimate load borne by the ore pillars is reached, the ore pillars will appear to fracture fissures (Figure 10(b)). After the completion of the third excavation stage, the stope at this time collapsed on a large scale, and stress concentration occurred in the boundary pillars on both sides of the stope (Figure 10(c)). In addition, after the end of the pillar stoping stage, the overlying rock strata collapsed in a large area, and its shape was similar to the "elliptical arch" type (Figure 10(d)).

4.4.2. Law of Rock Mass Movement, Deformation, and Failure. In Figure 11, the top and bottom plates of the stope had undergone displacement changes at different stages, and the subsidence of the surrounding rock of the stope roof was significantly greater than the displacement at the bottom plate. As each ore body was mined, the stope floor begun to arch upwards, the roof was bent downwards and sank, and the largest sinking area appeared in the center of the stope. In addition, due to the soft and inclination of the floor of the ore body, during the excavation process, the floor of the ore body was uplifted in the direction of the goaf. The pillars of various stopes and mine rooms had a tendency to break [30]. After the first stage ore body was excavated, the overlying rock of mine room \#1 and \#2 begun to sink, and the roof center had a downward bending and sinking trend (Figure 11(a)). After the second stage ore body was mined, the deformation of the stope will be further increased. Among them, the deformation and destruction areas of the stope were concentrated in the first stage mine rooms \#1, \#2, and the second stage (Figure 11(b)). After the three-stage ore body was mined, the maximum deformation area of the stope was concentrated in the second stage ore body, and the pillars of each stage have different degrees of shear displacement, and the maximum displacement was about $-1.2 \mathrm{~m}$ (Figure 11(c)). After the mining of the pillar, the overlying rock of the model stope collapsed on a large scale, and the collapse shape was similar to the stress distribution in Figure 10(d), which was "elliptical arch" (Figure 11(d)).

In summary, after each stage of ore body excavation, the maximum subsidence displacement occurred in the central area of the overlying rock, and stress concentration occurred at the pillar and stope boundary, resulting in shear deformation. At the synchronous distance, along the normal direction of the goaf, the farther away from the goaf, the smaller the displacement. In addition, at the same level in the horizontal direction, the displacement above the goaf is much greater than the displacement of the rock above the pillar. With the increase of the exposed roof span, the settlement of the overlying rock on the old roof of the stope also increases. On the other hand, the bulging phenomenon of the floor below the field is also moving forward dynamically. Thus, this phenomenon is consistent with the test results of similar materials [31-33].

4.4.3. Analysis of the Rock Mass Plastic Zone. As shown in Figure 12, after the first stage of mining was completed, the plastic zone mainly occurred near the toe of the open slope, the roof of the goaf, and the topsoil layer (Figure 12(a)). After the second stage of excavation was completed, the scope of the goaf will increase, resulting in a substantial increase in the scope of the stope's plastic zone, causing the production of plastic through the zone, which gradually extends upward into the indirect roof. In addition, with the mining of the mine room, each pillar had yielded. Due to the support of the pillar, the overlying rock had yielded, but the overall stability was basically stable. The reason is that the upper part of the ore body has a huge thick hard rock layer (medium to coarse crystalline dolomite), which has the ability to resist the tensile deformation of the rock body 


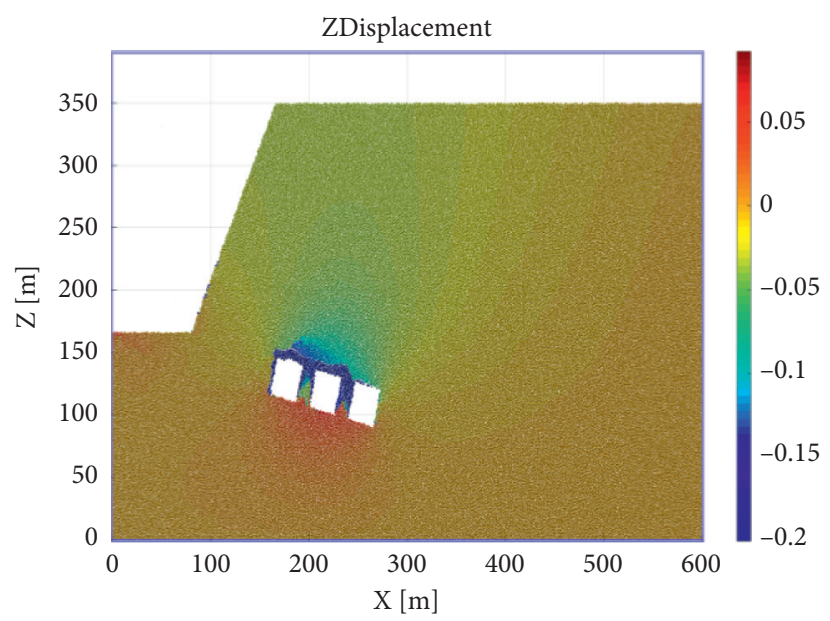

(a)

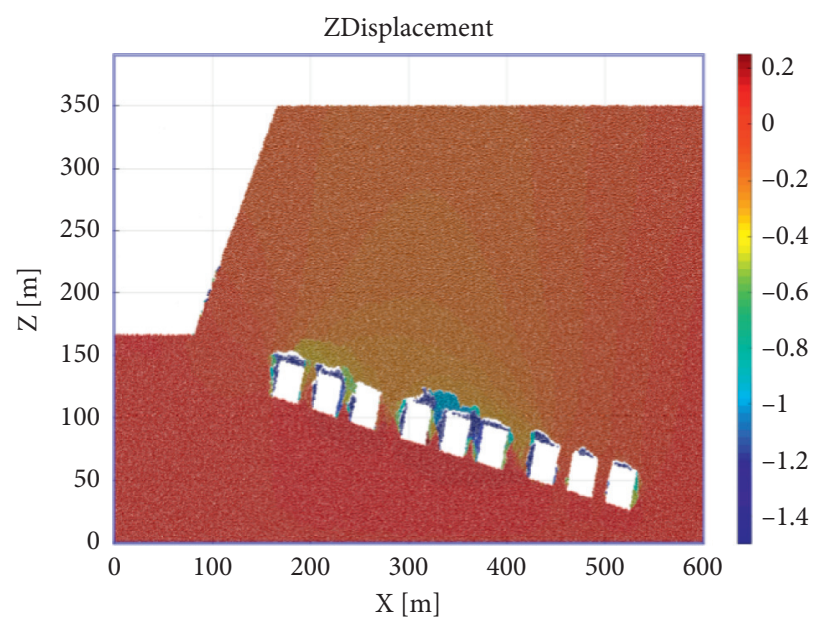

(c)



(b)

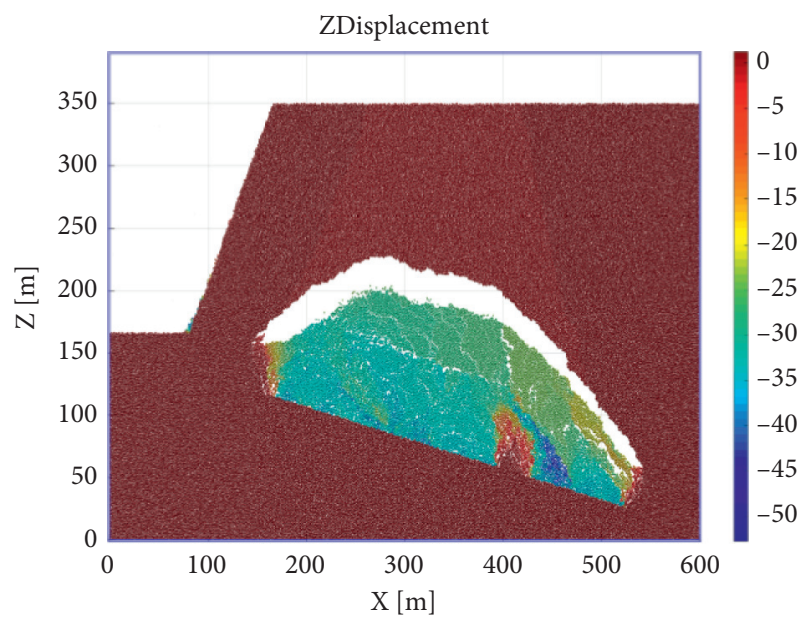

(d)

FIgURE 11: Displacement distribution of excavated rock mass in (a) the first stage, (b) the second stage, (c) the third stage, and (d) the stoping stage.

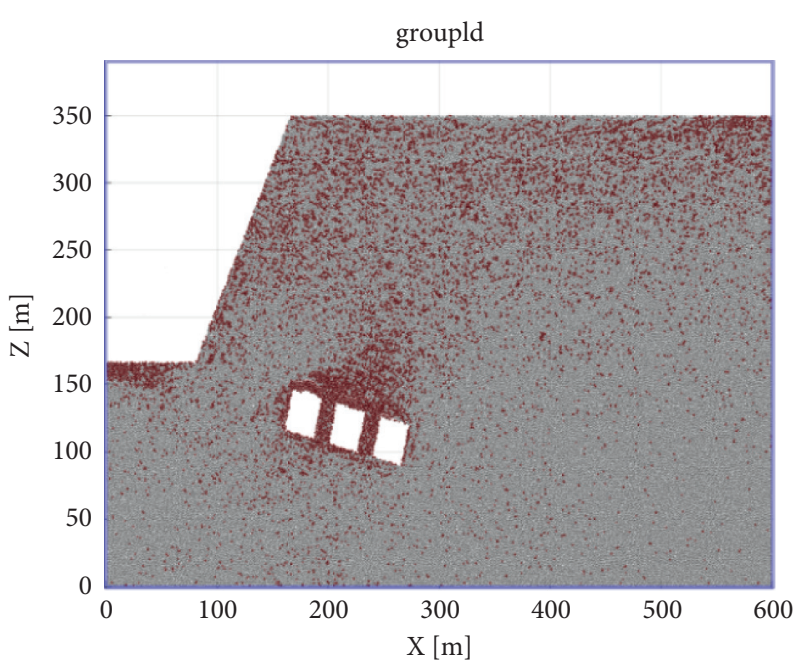

(a)

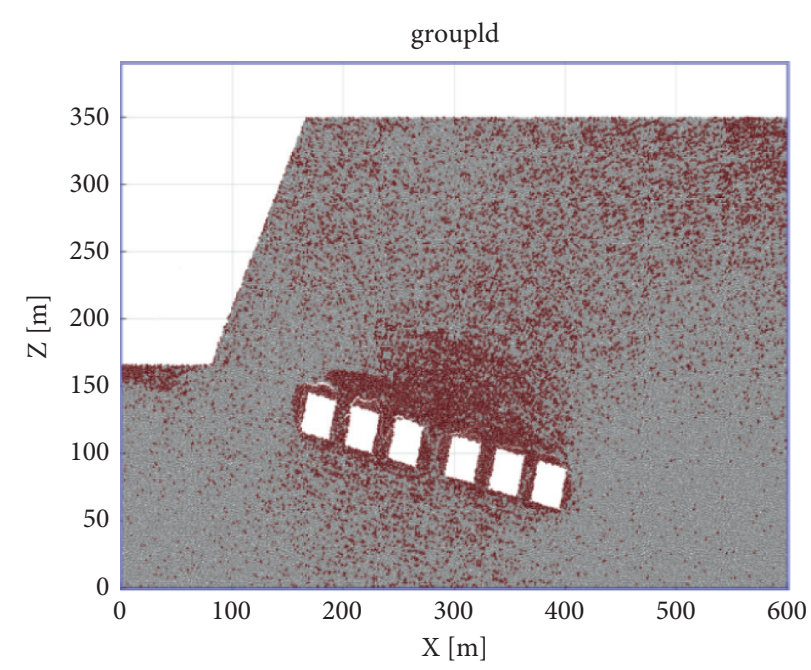

(b)

Figure 12: Continued. 


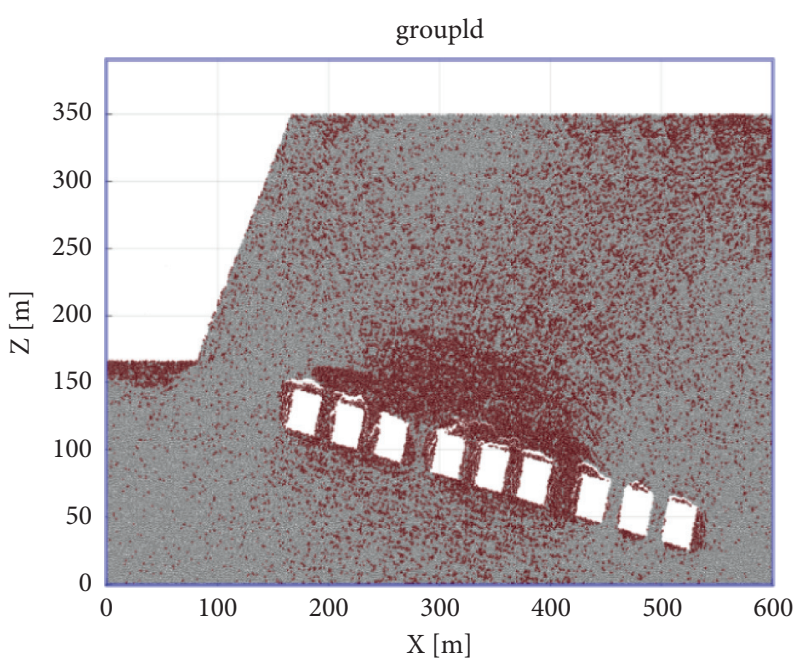

(c)



(d)

Figure 12: The plastic zone of excavated rock mass in (a) the first stage, (b) the second stage, (c) the third stage, and (d) the stoping stage.

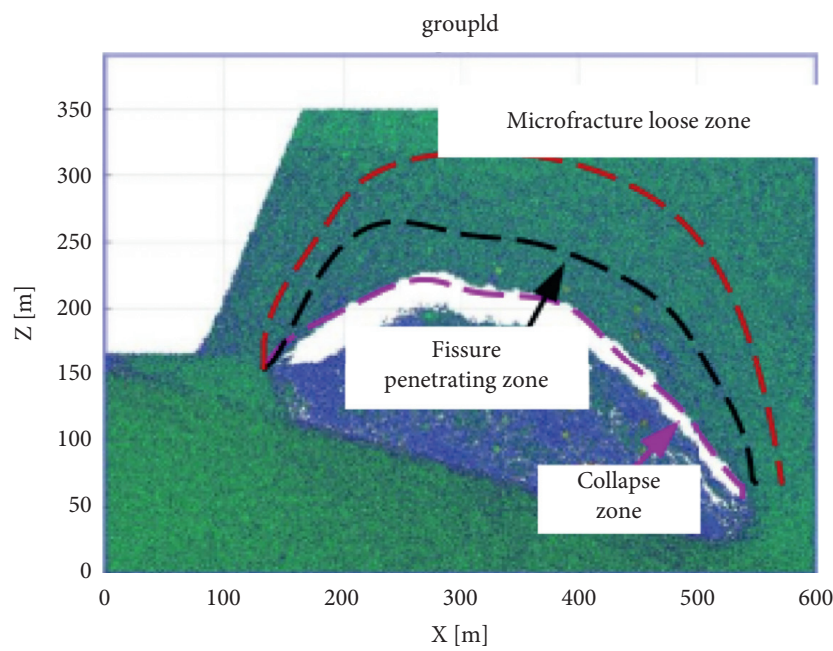

(a)

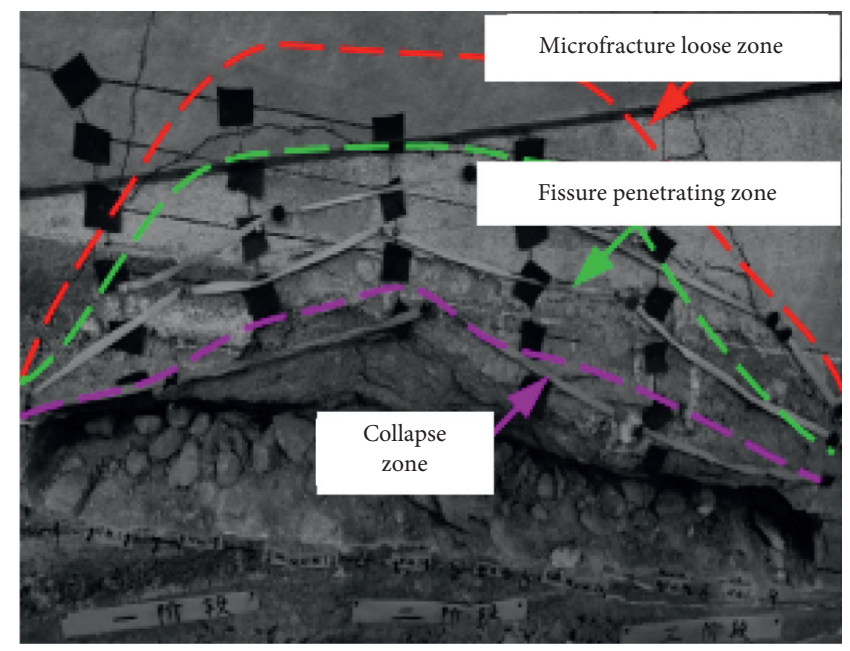

(b)

FIGURE 13: Comparison of collapse characteristics between numerical simulation and similar simulation under the slope height of $200 \mathrm{~m}$ and slope angle of $65^{\circ}$.

[34-37]. Therefore, the plastic penetration zone of the overlying strata does not form a penetration at the medium to coarse crystalline dolomite layer (Figure 12(b)). After the end of the third stage of mining, the plastic zone of the stope continued to increase, and part of the overlying rock above the pillar collapsed (Figure 12(c)). Finally, when all the pillars were stopped, the plastic zone above the stope was penetrated and the entire stope collapses in a large area. At this time, it can be found that the bottom floor of the stope is uplifted and destroyed (Figure 12(d)).

4.5. Comparison and Analysis with Similar Simulation Experiment Results. Similar model experiments and numerical simulation results show that when the room-pillar method is used to mine gently inclined phosphate ore bodies, the direct roof of the mined-out area collapses, a large number of fissures and separation layers are generated inside the indirect roof, and the rock formation is structurally damaged. In particular, the recovery of the two central pillars caused a sharp increase in the deformation area of the roof. However, due to the presence of medium to coarse-grained dolomite layers (large thickness and high strength) in the overlying rock, the direct roof and the lower part of the indirect roof in the mined-out area have a certain degree of plastic penetration. The upper part of the indirect roof and the overlying rock have no major failure. The linear elastic contact model built in MatDEM software follows Hooke's law and MooreCoulomb strength criterion, which cannot well reflect the rheological properties of real rock masses. Therefore, the 
numerical simulation results are different from similar simulation experiments (Figure 13), but the penetration position of the fissure and the deformation and failure range of the rock mass are basically consistent.

\section{Conclusions}

In this paper, through engineering geological survey, rock mechanics test, similar material experiment and MatDEM numerical simulation, the deformation and failure law and evolution characteristics of surrounding rock of open-pit converted underground stope were studied systematically. The following conclusions were drawn:

(1) Based on the law of rock mass movement, deformation, and failure, the direction of the underground stope rock layer movement points to the goaf, and the maximum horizontal displacement and vertical displacement appear at the upper boundary of the goaf (gravel-containing quartz sandstone). Along the inclination of the ore body, the farther the horizontal and vertical displacements are from the underground stope, the less the impact of mining stress. On the other hand, along the inclined vertical direction of the ore body, the farther the measuring point is from the stope, the smaller the range of mining influence.

(2) Numerical simulation results show that during the recovery process of the ore body, the rupture of the overlying strata of the stope has an obvious layered structure, with collapse zones, fissure penetrating zones, and microfracture loosen zones appearing from bottom to top. In addition, the movement and destruction of the overlying strata of the entire stope are an "elliptical arch."

(3) The results of similar simulation tests and numerical simulation are basically consistent. Specifically, after the phosphate ore body is converted from open-pit mining to underground mining, the direct roof of the underground stope is destroyed in an "elliptical arch." When the internal stress value of the pressure arch exceeds the ultimate strength of the rock layer, the rock layer will undergo compression failure, shear failure, tensile failure, or combined failure.

\section{Data Availability}

The data used to support the findings of this study are included within the article.

\section{Conflicts of Interest}

The authors declare that there are no conflicts of interest regarding the publication of this paper.

\section{Acknowledgments}

This work was supported by the National Natural Science Foundation of China (nos. 41702327 and 41867033), Postdoctoral Science Foundation of China (no. 2019M650144), and State Key Laboratory of Safety and Health for Metal Mines (zdsys2019-005). The authors acknowledge these supports.

\section{References}

[1] Z. G. Agioutantis, "Automated downtime recording and processing for continuous surface mining systems," International Journal of Surface Mining, Reclamation and Environment, vol. 8, no. 4, pp. 159-162, 1994.

[2] P. Liu, W. Zhou, Q. X. Cai, X. Shi, and G. Xu, "The thin coal seam (TCS) mining technology for open pit mines in China," Geotechnical \& Geological Engineering, vol. 36, no. 6, pp. 3627-3637, 2018.

[3] E. Bakhtavar and H. Mahmoudi, "Development of a scenariobased robust model for the optimal truck-shovel allocation in open-pit mining," Computers \& Operations Research, vol. 115, Article ID 104539, 2020.

[4] J. C. Branco, R. Rebbah, J. Duarte, and J. S. Baptista, "Risk assessment in the open pit mining industry-a short review," Studies in Systems, Decision and Control, vol. 202, pp. 13-21, 2019.

[5] S. Singgih, Y. M. Rahman, V. Vega, and S. Herry, "Rock mass classification for sedimentary rock masses in Indonesia coal mining areas," AIP Conference Proceedings, vol. 2245, no. 1, pp. 1-15, 2020.

[6] S. Xu, Y. H. Li, L. An, and Y. J. Yang, "Study on high and steep slope stability in condition of underground mining disturbance," Journal of Mining and Safety Engineering, vol. 29, no. 6, pp. 888-893, 2012.

[7] Q. H. Li, X. S. Li, J. B. Geng, and L. Luo, "FLAC3D numerical simulation of open-pit transformation to underground slope and stope stability," Nonferrous Metals, vol. 73, no. 2, pp. 5-10, 2021.

[8] Z. W. Wang, G. F. Song, and K. Ding, "Study on the ground movement in an open-pit mine in the case of combined surface and underground mining," Advances in Materials Science \& Engineering, vol. 2020, Article ID 8728653, 13 pages, 2020.

[9] M. James and D. Roussos, "A stochastic optimization formulation for the transition from open pit to underground mining," Optimization and Engineering, vol. 18, no. 3, pp. 793-813, 2017.

[10] J. Jakubec, L. Long, T. Nowicki, and D. Dyck, "Underground geotechnical and geological investigations at Ekati MineKoala north: case study," Lithos, vol. 76, no. 1-4, pp. 347-357, 2005.

[11] E. Bakhtavar and K. Shahriar, "Economical-mathematical analysis of transition from open-pit to underground mining," International Journal of Rock Mechanics and Mining Sciences, vol. 52, no. 9, pp. 79-88, 2015.

[12] R. K. Brummer, H. Li, A. Moss, and T. Casten, "The transition from open pit to underground mining: an unusual slope failure mechanism at Palabora," in Proceedings of the International Symposium on Stability of Rock Slopes in Open Pit Mining and Civil Engineering, pp. 411-420, Cape Town, Africa, April 2006.

[13] A. Mass, S. Diachenko, and P. Townsend, "Interaction between the block cave and the pit slopes at Palabora mine," Journal of the South African Institute of Mining and Metallurgy, vol. 106, no. 7, pp. 479-484, 2006.

[14] C. H. Li, Y. F. Wang, M. F. Cai, S. J. Miao, and L. P. Fan, "Slope deformation model of metal mines transferred underground mining from open-pit based on support vector machines," 
Journal of University of Science and Technology Beijing, vol. 31, no. 8, pp. 945-950, 2009.

[15] Y. M. Zhang, F. S. Ma, J. M. Xu, and H. Zhao, "Deformation laws of rock mass due to transform from open-pit to underground mining in high stress area," Rock and Soil Mechanics, vol. 32, no. S1, pp. 590-595, 2011.

[16] W. D. Song, J. X. Fu, and D. X. Wang, "Study on physical and numerical simulation of failure laws of wall rock due to transformation from open-pit to underground mining," Journal of China Coal Society, vol. 37, no. 2, pp. 186-191, 2012.

[17] T. B. Jia, "The Dynamic prediction on environment damage induced by the excavation from open-pit into underground mine," Journal of Safety Science and Technology, vol. 11, no. 3, pp. 99-104, 2015.

[18] Y. F. Wang, C. H. Li, and F. Cui, "Evolution mechanism of dynamic shock disaster caused by slope instability in transition from open-pit to underground mining," Mining and Metallurgical Engineering, vol. 33, no. 5, pp. 13-16, 2013.

[19] R. Wang, S. Yan, and J. B. Bai, "Theoretical analysis of damaged width \& instability mechanism of rib pillar in openpit highwall mining," Advances in Civil Engineering, vol. 2019, Article ID 6328702, 15 pages, 2019.

[20] X. S. Li, Y. C. Li, and S. S. Wu, "Experimental investigation into the influences of weathering on the mechanical properties of sedimentary rocks," Geofluids, vol. 2020, pp. 1-12, 2020.

[21] X. S. Li, Z. F. Liu, and S. Yang, "Similar physical modeling of roof stress and subsidence in room and pillar mining of a gently inclined medium-thick phosphate rock," Advances in Civil Engineering, vol. 2021, Article ID 6686981, 17 pages, 2021.

[22] X. S. Li, S. Yang, Y. M. Wang, W. Nie, and Z. Liu, "Macromicro response characteristics of surrounding rock and overlying strata towards the transition from open-pit to underground mining," Geofluids, vol. 2021, Article ID 5582218, 18 pages, 2021.

[23] X. S. Li, Y. M. Wang, K. Zhao, and S. Yang, "Research progress on the key problems in transition from open-pit to underground mining for metal mines," Metal Mine, vol. 2019, no. 12 , p. 20,2019

[24] N. X. Xu, J. Y. Zhang, H. Tian, G. Mei, and Q. Ge, "Discrete element modeling of strata and surface movement induced by mining under open-pit final slope," International Journal of Rock Mechanics and Mining Sciences, vol. 88, pp. 61-76, 2016.

[25] Y. Zhao, T. H. Yang, M. Bohnhoff et al., "Study of the rock mass failure process and mechanisms during the transformation from open-pit to underground mining based on microseismic monitoring," Rock Mechanics and Rock Engineering, vol. 51, no. 5, pp. 1473-1493, 2018.

[26] X. S. Li, J. B. Geng, Q. H. Li, W. Tian, and T. Zhou, "Behaviors and overlying strata failure law for underground filling of a gently inclined medium-thick phosphate deposit," Advances in Civil Engineering, vol. 2021, Article ID 3275525, 17 pages, 2021.

[27] X. S. Li, Y. M. Wang, S. Yang, J. Xiong, and K. Zhao, "Research progress in the mining technology of the slowly inclined, thin to medium thick phosphate rock transition from open-pit to underground mine," Applied Mathematics and Nonlinear Sciences, vol. 6, no. 1, pp. 319-334, 2021.

[28] X. S. Li, Y. M Wang, and K. Zhao, "Study on the law of ground pressure obliquity effect with gently inclined thin to medium thickness phosphate body from open-pit to underground," Solid State Technology, vol. 63, no. 4, pp. 6773-6781, 2020.
[29] A. K. Mohammad and M. Ali, "Slope stability analysis of sarcheshmeh copper mine west wall under seismic loads," Geotechnical \& Geological Engineering, vol. 37, no. 4, pp. 3141-3155, 2019.

[30] S. Vongpaisal, G. Li, and R. Pakalnis, "New development of expert system module for a decision-making on mine stope stability in underground blasthole mining operations," International Journal of Mining, Reclamation and Environment, vol. 25, no. 1, pp. 41-51, 2011.

[31] K. Zhao, X. Yu, S. J. Gu et al., "Stability of stope structure under different mining methods," Journal of Vibroengineering, vol. 21, no. 7, pp. 1945-1960, 2019.

[32] S. L. Ren, Z. G. Tao, M. C. He, S. H. Pang, M. N. Li, and H. T. Xu, "Stability analysis of open-pit gold mine slopes and optimization of mining scheme in inner Mongolia, China," Journal of Mountain Science, vol. 17, no. 12, pp. 2997-3011, 2020.

[33] X. S. Li, K. Peng, J. Peng, and D. Hou, "Effect of thermal damage on mechanical behavior of a fine-grained sandstone," Arabian Journal of Geosciences, vol. 14, p. 1212, 2021.

[34] M. Li, J. X. Zhang, G. H. Meng, Y. Gao, and A. Li, “Testing and modelling creep compression of waste rocks for backfill with different lithologies," International Journal of Rock Mechanics and Mining Sciences, vol. 125, Article ID 104170, 2020.

[35] M. Li, A. L. Li, J. X. Zhang, Y. Huang, and J. Li, "Effects of particle sizes on compressive deformation and particle breakage of gangue used for coal mine goaf backfill," Powder Technology, vol. 360, pp. 493-502, 2019.

[36] M. Li, J. X. Zhang, A. L. Li, and N. Zhou, "Reutilisation of coal gangue and fly ash as underground backfill materials for surface subsidence control," Journal of Cleaner Production, vol. 254, Article ID 120113, 2020.

[37] X. S. Li, Y. M. Wang, and K. Zhao, "Research on deformation and failure character of underground surrounding rock and overlying strata transition from open-pit to underground mining," Solid State Technology, vol. 63, no. 4, pp. 6732-6757, 2020. 